Ms. Amy Manheim (EE 521)

Energy-Related Inventions Program

U.S. Department of Energy

1000 Independence Avenue, SW

Mail Stop 5E-052

Washington, DC 20585

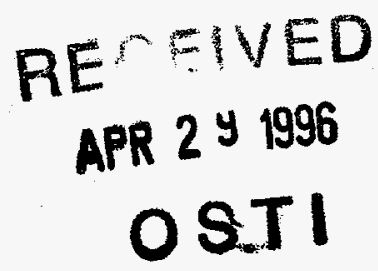

Dear Ms. Manheim:

Confirming our recent telephone conversation, I am pleased to submit a progress report on the DOE grant "Tribopolymerization as an Anti-Wear Mechanism." This was Recommendation Number 584 under the DOE/NIST Energy-Related Inventions Program.

As you will see by the summary of highlights of our activities under this grant, considerable progress was made in several related and connected areas. We have (a) completed the construction of a new high-load, high-speed machine, (b) used it for studies of new anti-wear compounds designed for high-temperature applications, (c) received the first U.S. Patent on our discoveries in applying the concept to ceramic lubrication, (d) taken advantage of related NSF-sponsored research on this topic as a fundamental foundation, and $(e)$ completed arrangements with Triad Investors, Inc. - now with an office here at the Virginia Tech Corporate Research Center -- as a mechanism to further develop the application, licensing, and marketing of our technology. This last item is particularly exciting since it focusses on bringing the developments in our tribopolymerization concept into the marketplace -- the central theme of the Energy-Related Inventions Program.

We appreciate the support by the Department of Energy on this project. If there are any questions about our report or if more information is needed, I can be reached as follows:

Telephone: $\quad 540-231-7193$

Fax:

540-231-9100

ө-mail:

mfurey@vt.edu

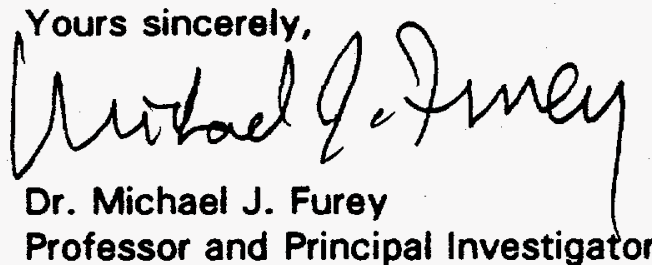

Enclosure

cc: Dr. Czeslaw Kajdas

Dr. Walter F. O'Brien

Mr. Lee E. Martin

\section{DISCLAIMER}

This report was prepared as an account of work sponsored by an agency of the United States Government. Neither the United States Government nor any agency thereof, nor any of their employees, makes any warranty, express or implied, or assumes any legal liability or responsibility for the accuracy, completeness, or usefulness of any information, apparatus, product, or process disclosed, or represents that its use would not infringe privately owned rights. Reference herein to any specific commercial product, process, or service by trade name, trademark, manufacturer, or otherwise does not necessarily constitute or imply its endorsement, recommendation, or favoring by the United States Government or any agency thereof. The views and opinions of authors expressed herein do not necessarily state or reflect those of the United States Government or any agency thereof. 


\title{
Progress Report on
}

\section{Tribopolymerization as an Anti-Wear Mechanism}

\author{
for the
}

\author{
Energy-Related Inventions Program \\ Recommendation Number 584 \\ U.S. Department of Energy \\ Washington, DC 20585
}

\author{
submitted by \\ Dr. Michael J. Furey \\ Principal Investigator \\ Department of Mechanical Engineering \\ Virginia Polytechnic Institute and State University \\ Blacksburg, Virginia 24061-0238
}

December 1995 


\section{SUMMARY}

During the first phase of this project, significant progress was made in several of the connected issues that make up the objectives of this grant. The central thrust or theme of our work under the DOE/ERIP grant is to carry out prototype testing of the concept of tribopolymerization as a novel mechanism of boundary lubrication -under more severe, high-load, high-speed conditions that are more likely to exist in field applications. We see this as an important step in attracting industries to license and market the results of our new technology. In addition, we have began to explore other potential, energy-saving applications of the concept of tribopolymerization. There exploratory studies are quite promising; they are likely to open new doors in industrial applications. To carry out the experimental part of this program, a new device has been built. Highlights of these and other developments are given in the following paragraphs.

\section{New Hiah Frictional Eneray Device}

A new high-load, high-speed pin-on-disk machine has been constructed, instrumented, and used for initial high frictional energy tests with ceramic-on-ceramic, steel-on-steel, and ceramic-on-steel systems. The machine is constructed as an addon unit to a heavy-duty milling machine. Our previous pin-on-disk device could be operated at applied loads to $20 \mathrm{~N}$ and sliding speeds up to $0.25 \mathrm{~m} / \mathrm{s}$. The new machine can be used at loads to $160 \mathrm{~N}$ and speeds to $1.0 \mathrm{~m} / \mathrm{s}$-. an increase in frictional energy of 32-fold. These conditions produce higher surface temperatures and are more closely related to more severe lubrication regimes encountered in many field applications. In any event, our experimental capabilities have been significantly extended by the construction of the new device. The addition of heating elements as well as an enclosure for vapor phase studies is being examined.

\section{Ceramic/Steel Combinations}

Using the high-load pin-on-disk apparatus, several tests have been run on four tribological systems, namely (a) alumina-on-alumina, (b) alumina-on-steel, (c) steel-onalumina, and (d) steel-on-steel. This is important since some ceramic components being considered for tribological applications are in sliding contact with steel and alloy steels. Our results show that the mechanism of tribopolymerization can function to reduce wear significantly in all four of the above combinations at high loads -- the effect depending on the monomer chosen.

\section{New Monomers Examined}

New compounds designed not only to function (polymerize) at higher temperatures but to form protective polymeric films capable of withstanding higher temperatures are being investigated as wear-reducing agents. The initial results -obtained with condensation-type monomers containing aromatic ring structures -- are quite promising. 


\section{Vapor Phase Lubrication}

We have demonstrated that the concept of tribopolymerization is extremely effective in reducing ceramic wear in the vapor phase. In pin-on-disk tests using dry nitrogen as the carrier gas, wear-reductions of $95-99 \%$ were obtained by the use of selected addition-type monomers at very low concentrations in the gas. The wearreductions are more pronounced at higher temperatures -- a finding which could have practical applications in the lubrication of high-temperature, low heat rejection engines.

\section{U.S. Patent Issued}

The U.S. Patent on our discoveries finally issued on April 18, 1995. It is "Compositions for Reducing Wear on Ceramic Surfaces," U.S. Patent 5,407,601; Michael J. Furey and Czeslaw Kajdas, inventors. A copy will be sent to the EnergyRelated Inventions Program if wanted.

\section{Triad Investors, Inc. and Industrial Applications}

A collaborative agreement has been made between Virginia Tech Intellectual Properties, our Office of Sponsored Research, and Triad Investors, Inc. of Baltimore to explore the further application, development, marketing, and licensing of technology resulting from our tribopolymerization concept. Triad, which now has an office in the Virginia Tech Corporate Research Center, is supporting additional research in three areas, namely: (a) fuel additives for 2-stroke gasoline engines to achieve lubrication and wear control without excessive emission lour compounds are ashless and thus offer promise as fuel lubricity additives); (b) tribopolymerization as a novel method of lubricating ceramic machining/cutting tools, reducing friction, tool wear and down time -- thus saving energy and money; and (c) vapor phase lubrication of metals and ceramics at high temperatures. The initial results in these severe applications are quite promising. Patent applications in two of the areas are being prepared.

We believe that the Triad connection will enhance and speed up the bringing of our technology to the market-place.

\section{Connections with NSF-Sponsored Research on Tribopolymerization}

Our ERIP project on tribopolymerization has greatly benefited from the results of related fundamental research on this concept supported by the National Science Foundation. Our second NSF proposal on this mechanism, one dealing with ceramic tribology, comes to an end this month. But the research carried out by graduate students Chris Smith and Ben Tritt has also helped the DOE project. In addition, discussions in the Summer (1995) with research colleagues Drs. Czeslaw Kajdas and Roman Kempinski aided in the planning and direction of future work. 


\section{Current Work and Future Plans}

Since August 1995, one graduate student, Jeff Valentino, has been working on the DOE-ERIP project carrying out tests in the new high-load, high-speed pin-ondisk device using various selected monomers in hexadecane and synthetic oils. These include new chemical structures designed for high temperature applications. Improvements have been made in the operation and control of the equipment as well as in the acquisition and interpretation of data.

The main focus of our continued and future work on the topic of tribopolymerization under the DOE-ERIp grant is to acquire that data and information - proof-of-performance or prototype demonstration -- which will help us to bring our technology into the marketplace. As you know, this is the primary theme or objective of the ERIP program.

Drs. Kajdas and Kempinski will return to Virginia Tech to work with me in the Summer of 1996. In addition, I plan to make exploratory contacts with various industries and institutes in January and during the Spring. We are greatly encouraged by the results obtained so far, particularly in the connections made with regard to possible industrial applications. 